\title{
O ACORDO DE SÓCIOS COMO MÉTODO DE PREVENÇÃO DE CONFLITOS
}

\author{
Neimar Batista*
}

\begin{abstract}
Sumário: Introdução. 1. Conceito e Natureza Jurídica do Acordo de Sócios. 2. Amparo e Limitações Legislativas. 3. O Acordo de Sócios Como Método de Prevenção de Conflitos. Conclusão.
\end{abstract}

- RESUMO : A atividade empresarial representa a comunhão de interesses com o objetivo de angariar lucros e garantir rentabilidade. Com esse intuito, muitos se esquecem que a conjugação entre interesse e lucro pode redundar em conflitos, os quais repercutirão inevitavelmente na sociedade empresária. Nessa seara, o acordo de sócios se revela em uma maneira eficaz de se evitar litígios e assegurar a integridade dos interesses inicialmente previstos pelos seus integrantes. $O$ presente estudo pretende situar o acordo de sócios na esfera legal no âmbito de duas espécies de empreendimentos - a sociedade empreendedor-investidor e a sociedade familiar - , bem como identificar seus elementos constitutivos e limitativos, além de destacar quais os litígios comumente prevenidos por sua adoção.

- Palavras chave: Acordo de Sócios. Contratos. Prevenção de Litígios. Abuso de Direito. Boa-fé objetiva.

- ABSTRACT: The business activity is the commonality of interests with the aim of raising profits and ensure profitability. To that end, many forget that the combination of interest and profit can lead to conflicts, which inevitably have repercussions in the corporation. In this area, the agreement of partners is revealed in an effective way to avoid disputes and ensure the integrity of the interests initially planned by its members. This study intended to delineate the agreement of partners in the legal sphere in scope of two kinds of enterprises - the business man-inventor and the family company - and identify its constituent elements and limitations, in addition to highlighting which disputes often prevented their adoption by .

- Keywords: Business Partners Agreement. Contracts. Prevention of Disputes. Abuse of rigths. Objective good faith.

\section{Introdução}

A evolução da atividade mercantil está baseada na junção de determinados interesses para o desenvolvimento econômico. Nesse sentido, o direito empresarial vem evoluindo para dar suporte às mais diversas espécies de situações criadas na constituição de uma sociedade empresária.

Existem duas espécies de "acordos de vontades" que se destacam nas sociedades mercantis brasileiras: a primeira origina-se da reunião de dois interesses, um é o empreendedor, que possui a idéia, e o segundo o investidor, que detém o capital financeiro necessário ao desenvolvimento dessa idéia; a segunda espécie é a

\footnotetext{
*Advogado, Pós Graduado em Direito Processual Civil pelo IBEJ - Instituto Brasileiro de Estudos Jurídicos, Pós Graduado em Direito Processual Civil pela Pontifícia Universidade Católica do Paraná, Mestrando em Direito Empresarial e Cidadania pela UNICURITIBA. Membro do Projeto de Pesquisa "Livre Iniciativa e Dignidade Humana - Ano II", do Programa de Mestrado em Direito do Centro Universitário de Curitiba - UNICURITIBA.
} 
sociedade familiar, geralmente originária da manufatura agrícola ou artesanal que se desenvolveu e se transformou em um empreendimento gerido por toda a família, ou parte dela.

Essas espécies societárias possuem características próprias e peculiares, diferenciando-se tanto na sua constituição, no seu desenvolvimento e principalmente na sua sucessão, conferindo ao direito empresarial uma especial área de estudo.

Os tipos sociais mais característicos que serão abordados envolvem a sociedade de responsabilidade limitada e a sociedades por ações, que são as mais difundidas na constituição dessas espécies de sociedades empresárias.

O presente estudo, apesar de aplicável a toda espécie de sociedade empresária, tem em foco esses empreendimentos, baseados em interesses bastante típicos, os quais, não raro, após a empolgação inicial, ou no caso de sucessão familiar, podem gerar conflitos entre os sócios, acabando na extinção ou quebra do atividade.

Nesse sentido, o acordo de sócios tem se mostrado uma forma eficaz de se prevenir conflitos, tanto na sucessão empresarial, quanto nas questões familiares, razão pela qual o presente estudo terá por objetivo principal situar as principais formas de conflito que podem surgir nessas espécies de sociedades empresárias, demonstrando quais os benefícios do acordo de sócios na solução de eventuais litígios.

Antes, porém, demonstrar-se-á quais os requisitos de um acordo de sócios, qual sua natureza jurídica, os limites para sua formação e a legislação aplicável, de forma a assegurar sua validade e eficácia quando de sua execução.

\section{1 - Conceito e Natureza Jurídica do Acordo de Sócios:}

$\mathrm{O}$ acordo de sócios é negócio jurídico de direito privado, porém, quanto às obrigações, pode ter várias conotações, a saber:

1. Unilateral: Quando apenas um dos sócios ou grupo de sócios, possui obrigações a cumprir. Modesto Carvalhosa exemplifica essa espécie de acordo em situações onde há modificação da posição de acionistas, passando ele de controlador para minoritário, ocasião em que os majoritários obrigam-se a elegê-lo para cargo administrativo; ou ainda no ingresso de minoritários, que se obrigam a subscrever o capital na proporção de suas participações, etc... ;

2. Bilateral: "...é o acordo pelo qual são atribuídas obrigações recíprocas, concorrentes e opostas para cada uma das partes convenentes, de forma que cada uma delas terá condições de exigir o cumprimento do pactuado perante a outra parte." ${ }^{2}$ Ex: Acordos para estabilizar o poder de controle em uma companhia entre dois ou mais grupos.

\footnotetext{
${ }^{1}$ CARVAlHOSA, Modesto. Acordo de Acionistas. São Paulo: Saraiva, 1984, pág. 51, citado por BERTOLDI, MARCELO M. Acordo de Acionistas. São Paulo: Editora Revista dos Tribunais, 2006, pág. 44.

${ }^{2}$ BERTOLDI, MARCELO M. Acordo de Acionistas. São Paulo: Editora Revista dos Tribunais, 2006, pág. 45.
} 
3. Plurilateral: Acordo no qual "...cada parte adquire direitos e contrai obrigações com um objetivo comum, sem que haja contraposições de interesses, mas, sim, confluência deles para uma mesma finalidade." ${ }^{3}$ Exemplo dessa situação é aquela situação onde os acionistas comprometem-se a seguir uma determinada política de investimentos em ocasiões predeterminadas pelo acordo.

Um ponto crucial nessa diferenciação reside no fato de que apenas no acordo bilateral é que algum dos acionistas pode invocar o princípio da exceptio non adimpleti contractus (exceção do contrato não cumprido), uma vez que no acordo unilateral apenas uma das partes possui obrigações, enquanto que no prurilateral "cada signatário contraiu seu compromisso frente a todos, e não pode ser liberado de suas obrigações porque um dos demais haja falhado com a sua."

Na definição de Barbi Filho o acordo de sócios "possui a natureza jurídica de negócio jurídico de direito privado, sendo um contrato civil, nominado, parassocial, em relação à companhia, preliminar, plurilateral quanto aos interesses que congrega, podendo ser plurilateral, bilateral ou unilateral quanto às obrigações que impõe às partes. ${ }^{15}$

Dessa contextualização pode se extrair a principal controvérsia sobre o assunto, ou seja, pode o acordo de sócios ser caracterizado como contrato preliminar?

Marcelo M. Bertoldi discorda, afirmando o seguinte:

"Muito embora grande parte da doutrina classifique o acordo de acionistas como uma espécie de contrato preliminar, não podemos concordar com tal posicionamento. Como se sabe, o contrato preliminar trata-se daquela espécie de pacto em que as partes se obrigam a concluir um determinado contrato, cujo conteúdo jurídico e econômico já foi previamente definido. Isso se dá sempre que os contratantes entendam não ser possível ou conveniente contratar imediatamente de forma definitiva, optando por lançar mão dessa espécie de obrigação que assegura às partes que um contrato principal e definitivo será firmado em época prevista. Tem-se, então, o contrato definitivo, que é a razão de existir e o objetivo único do pré-contrato.

No acordo de acionistas, a base fundamental das obrigações nele estampadas diz respeito à contratação definitiva da obrigação de declarar a vontade num determinado sentido (acordo de voto) ou, então, a obrigação de dar o direito de opção, preferência etc., a outrem em caso de transação de ações (acordo de bloqueio). Não se está diante de um pacto que obrigue os contratantes a efetuar outro contrato mediante a previsão das bases do negócio. No caso do acordo de voto, é evidente que o exercício do direito de voto jamais poderá ser tido como um "contrato" posterior ao acordo. (...)

${ }^{3}$ BERTOLDI, MARCELO M. Acordo de Acionistas. São Paulo: Editora Revista dos Tribunais, 2006, pág. 45/46.

${ }^{4}$ BARBI FILHO, Celso. Acordo de acionista. Belo Horizonte: Del Rey, 1993, pág. 72.

${ }^{5}$ BARBI FILHO, Celso. Acordo de acionista. Belo Horizonte: Del Rey, 1993, pág. 39. 
(...)

Ao contrário do que se possa imaginar, o fato de o acordo de acionistas, no mais das vezes, não se tratar de contrato preliminar, em nada afeta a possibilidade de sua execução específica, nos termos do que preceitua o $\S 3^{\circ}$ do art. 118 da Lei $6.404 / 1976$, que, ao estabelecer que "nas condições previstas no acordo, os acionistas podem promover a execução específica das obrigações assumidas", prevê a possibilidade de realização, in natura, dos efeitos pretendidos pelas partes no acordo, mesmo na hipótese de qualquer delas vir a descumpri-lo, evitando sua simples resolução por perdas e danos. (...)

Tal distinção não se apresenta como mero exercício de raciocínio jurídico, distanciado de conseqüências práticas; pelo contrário, tem relevância fundamental para esta investigação, na medida em que, entendendo tratar-se o acordo de acionistas de um contrato preliminar, para a sua execução específica, incidirá a disposição do art. 466-B do Código de Processo Civil, que determina que, "se aquele que se comprometeu a concluir um contrato não cumprir a obrigação, a outra parte, sendo isso possível e não excluído pelo título, poderá obter uma sentença que produza o mesmo efeito do contrato a ser firmado". Por outro lado, acaso prevaleça o entendimento aqui defendido de que o acordo de acionistas é contrato principal, tal situação subsume-se à hipótese do art. 466-A daquele mesmo diploma legal, onde é previsto que, "condenado o devedor a emitir declaração de vontade, a sentença, uma vez transitada em julgado, produzirá todos os efeitos da declaração não emitida". (...).

Como se viu, a discussão posta em análise é muito pertinente, pois em se admitindo o caráter pré-contratual aos acordos de sócios, haveria nítido prejuízo ao se executar determinada obrigação descumprida por um dos aderentes.

Barbi Filho, ao contrário de Marcelo M. Bertoldi, afirma que "a própria Lei 6.404/1976, ao estabelecer a possibilidade de execução específica das obrigações assumidas no acordo de acionistas, reconhece a sua natureza de contrato preliminar"6.

Na tentativa de dirimir a controvérsia, é prudente buscar os ensinamentos de insignes civilistas, a fim de verificar se o acordo de sócios é ou não um contrato preliminar.

Na dicção de Maria Helena Diniz, contrato preliminar é assim definido:

"Contrato preliminar (pactum de contrahendo) não é uma simples negociação, por ser um contrato que traça os contornos de um contrato final que se pretende efetivar no momento oportuno, gerando direito e deveres para as partes que assumem a obrigação de um futuro contrahere, isto é, de contrair contrato definitivo. Trata-se de uma promessa de contratar, pela qual uma ou ambas as partes firmatárias se comprometem a concluir, no porvir, um contrato definitivo. Por exemplo, promessa de compra e venda (RT, 712:169; RJ, 149;97, 92:250). ."

\footnotetext{
${ }^{6}$ BARBI FILHO, Celso. Acordo de acionista. Belo Horizonte: Del Rey, 1993, pág. 116.

${ }^{7}$ DINIZ Maria Helena. Código Civil Anotado, 13ª Edição. São Paulo: Saraiva, 2008, pág. 386.
} 
Orlando Gomes conceitua pré-contrato como "convenção pela qual as partes criam em favor de uma delas, ou de cada qual, a faculdade de exigir a imediata eficácia de contrato que projetaram." ${ }^{8}$

Ainda a guisa de caracterizar essa peculiaridade do acordo de sócios, é prudente destacar os ensinamentos de Silvio Rodrigues:

"O contrato definitivo tem por objeto, como é óbvio, criar vários tipos de obrigações para os contraentes. Assim, a compra e venda impõe ao vendedor o mister de entregar a coisa e, ao comprador, o de entregar o preço; o contrato de locação de imóvel obriga o locador a garantir ao locatário o uso pacífico da coisa, e este a pagar um aluguel ao senhorio etc. Portanto, cada qual destes ajustes tem um objeto peculiar e as partes que a eles recorreram visam obter esse fim típico em questão.

"Entretanto, o contrato preliminar (pacto de contrahendo) é uma espécie de convenção, cujo objeto é sempre o mesmo, ou seja, a realização de um contrato definitivo. Com efeito, o contrato preliminar tem sempre por objeto a efetivação de um contrato definitivo. As partes que, prometem, reciprocamente, que ultimarão, em tempo adequado, um contrato definitivo de compra e venda; quando, num ajuste preliminar, uma das partes prometeu à outra uma fiança, esse contrato preliminar cria para o promitente a obrigação de, oportunamente, prestar a fiança apalavrada.

"Por conseguinte, o contrato preliminar mostra-se portador de uma característica constante, isto é, a de ter por escopo, sempre, a realização de um contrato definitivo." $"$

Conforme se extrai das explicações e definições acima, o acordo de sócios tem maiores características de contrato definitivo que de pré-contrato ou contrato preliminar, pois são poucas as situações em que se prevê a consolidação da obrigação em um instrumento futuro, predominando as hipóteses em que os aderentes contraem obrigações de execução imediata.

Sendo assim, a contextualização do Marcelo M. Bertoldi parece ser a mais correta, pois no acordo de sócios se estabelece um verdadeiro contrato, com obrigações imediatas e subseqüentes à sua adesão.

Assim, contextualizado, pode se dizer quanto à natureza jurídica que o acordo de sócios é um negócio jurídico privado, de natureza contratual e informal, pois contém obrigações imediatas sem forma prevista em lei, parassocial, pois não constará necessariamente dos estatutos ou contrato social da empresa, unilateral, bilateral ou plurilateral quanto às obrigações, pois pode gerar obrigações à uma das partes, às duas partes, ou à várias partes simultaneamente.

Essa definição, portanto, melhor situaria natureza jurídica do acordo de sócios na esfera jurídica.

\section{2 - $\quad$ Amparo e Limitações Legislativas}

O acordo de sócios, no caso das sociedades anônimas, possui disposição expressa no artigo 118 da Lei 6.404/1976, porém, unicamente para limitar situações 
que envolvam compra e venda de ações, preferência para adquiri-las e exercício de voto ou poder de controle em sociedades anônimas de capital aberto.

Contudo, isso não implica em limitar o âmbito das obrigações que podem ser contraídas no acordo de sócios, valendo lembrar que o artigo 118 não impõe qualquer limitação para situações que não envolvam às nele mencionadas.

Vale dizer, assim, que toda a legislação pertinente às obrigações e aos contratos em geral são aplicáveis à espécie, obedecendo o previsto no artigo 122 do Código Civil:

Art. 122. São lícitas, em geral, todas as condições não contrárias à lei, à ordem pública ou aos bons costumes; entre as condições defesas se incluem as que privarem de todo efeito o negócio jurídico, ou o sujeitarem ao puro arbítrio de uma das partes.

Como se vê, o Acordo de Sócios está subsumido às condições gerais do negócio jurídico, merecendo aqui uma especial referência à disposição contida no artigo 187 do Código Civil, in ver bis:

Art. 187. Também comete ato ilícito o titular de um direito que, ao exercêlo, excede manifestamente os limites impostos pelo seu fim econômico ou social, pela boa-fé ou pelos bons costumes.

Nesse sentido, não podem os sócios exceder manifestamente os direitos que lhes conferem essa característica no intuído de lesar a outros sócios ou grupo de sócios, ou ainda, com o objetivo específico de angariar pra si vantagem manifestamente ilícita em detrimento de outros, ou valer-se do acordo de sócios contrariamente ao objeto da empresa envolvida.

Vale dizer que no acordo de sócios a boa-fé é, antes de mais nada, um requisito indispensável à sua validade e eficácia, aplicando-se ainda às suas disposições o previsto no artigo 422 do Código Civil.

A boa-fé é recepcionada amplamente pelo direito societário, conforme bem acentua Judith Martins Costa:

O Direito Societário recebe com traços particulares o dever de respeitar a confiança em razão da affectio societatis que potencializa os deveres de confiança. Por isso mesmo o venire aí incide com intensidade particular, mormente na relação intra-societária. ${ }^{10}$ in ver bis:

Ainda a esse respeito, merece destaque a lição de Fábio Konder Comparato,

(...) Ora, essa exigência de perseverança em certo e determinado acordo social - único e infungível - acarreta, por via de conseqüência, a exigência de acendrada boa-fé. Característica de actio pro socio é que se deixa condenar pelo inadimplemento de uma de suas obrigações contratuais por insignificante que seja,

\footnotetext{
${ }^{8}$ GOMES, Orlando. Contratos. Rio de Janeiro: Forense, 1998, pág. 135.

${ }^{9}$ RODRIGUES, Silvio, Direito Civil, Volume 3. São Paulo: Saraiva, 1999, pág. 37.

${ }^{10}$ MARTINS-COSTA, Judith. A Boa-Fé no Direito Privado. 1. ed., 2. tiragem. São Paulo: Editora Revista dosTribunais, 2000, p. 117.
} 
comete um ato de grave malícia (dolus malus) e incorre na infâmia.

A affectio societatis é, portanto, não um elemento exclusivo do contrato de sociedade, distinguindo-o dos demais contratos, mas um critério interpretativo dos direitos e responsabilidades dos sócios entre si, em vista do interesse comum. Quer isto significar que a sociedade não é a única relação jurídica marcada por esse estado de ânimo continuativo, mas que ele comanda, na sociedade, uma exacerbação do cuidado e diligência próprios de um contrato bonae fidei. Em especial, o sócio que descumpre disposição estatutária e, sobretudo, contratual (pois a relação convencional é mais pessoal e concreta que a submissão a normas estatutárias), como é o caso de acordos de acionistas numa sociedade anônima, pratica falta particularmente grave sob o aspecto da ética societária; ele se põe em contradição com sua anterior estipulação ou declaração de vontade, revelando-se pessoa pouco confiável enquanto sócio (venire contra factum proprium").

Há, assim, dois elementos componentes da affectio ou bona fides societatis, representativos do duplo aspecto dessa relação: a fidelidade e a confiança. A fidelidade é o escrupuloso respeito à palavra dada e ao entendimento recíproco que presidiu à constituição da sociedade, ainda que o quadro social se haja alterado, mesmo completamente. Por outro lado, a confiança é também um dever do sócio para com os demais, dever de tratá-los não

como contrapartes, num contrato bilateral em que cada qual persegue interesses individuais, mas como colaboradores na realização de um interesse comum. ${ }^{11}$

Outro ponto que merece atenção é que onde aparentemente ocorra simples exercício regular de um direito, pode haver abuso com intuito de prejudicar terceiros. Nesse caso, aparece a figura do abuso de direito, que se constitui em atos aparentemente lícitos que prejudicam os demais sócios, sendo que a boa-fé objetiva é um dos elementos identificadores dessa hipótese de ato ilícito.

Segundo Maria Helena Diniz, no ato abusivo "há violação da finalidade econômica ou social. O abuso é manifesto, ou seja, o direito é exercido de forma ostensivamente ofensiva à justiça." ${ }^{\prime 2}$

Assim, violaria a boa-fé objetiva e caracterizaria abuso de direito, o acordo de sócios realizado no intuito de excluir da sociedade determinado sócio ou grupo de sócios, ou ainda, com vistas a alterar o Estatuto ou Contrato social com objetivo de privilegiar determinada categoria de sócios, etc...

Porém, o ato abusivo pode também estar contido em detém estar contido em determinadas ações decorrentes dos acordos de sócios, havendo que se destacar que desnecessário o dolo (ou manifesto intuito lesivo, conforme alega Maria Helena Diniz), para caracterização do abuso de direito na relação societária.

${ }^{11}$ COMPARATO, Fabio Konder. Restrições à circulação de ações em companhia fechada: "nova et vetera" Revista de Direito Mercantil, São Paulo: Revista dos Tribunais, nº 36/65, p. 67-71. 1979.

${ }^{12}$ DINIZ Maria Helena. Código Civil Anotado, $13^{a}$ Edição. São Paulo: Saraiva, 2008, pág. 208; 
A teoria objetiva, ou finalista, também considera "abusivo e antijurídico o exercício contrário à finalidade do direito, de forma que inadmissível se configurava aquele exercício que contrariasse o fim para o qual o direito foi outorgado"13

Assim, aquele que usar o acordo de sócios contrariando a finalidade para a qual ele foi inicialmente concebido, estará agindo com abuso de direito e, fatalmente, poderá ter invalidada sua atitude por caracterizar ato ilícito, tal como previsto em nosso ordenamento civil (artigo 187 do Código Civil).

Enfim, nada mais correto e justo que se aplicar em uma relação entre sócios o dever de lealdade que se exige para a consecução de um objetivo comum, como deveria ocorrer em toda empresa.

\section{3 - O Acordo de Sócios Como Método de Prevenção de Conflitos:}

Como se viu anteriormente, o acordo de sócios é um contrato celebrado entre sócios de uma determinada empresa, onde se estabelecem direitos e obrigações que devem ser respeitadas entre os contraentes.

A lei 6.404/1976 prevê algumas espécies de acordos de sócios, porém, não restringe sua amplitude. De igual sorte, não há limitação para os casos não previstos no artigo 118 da referida Lei, a não ser àquelas impostas a todo negócio jurídico, conforme exposto anteriormente.

Sendo assim, cabe aqui restringir o âmbito do presente estudo para os casos mencionados na introdução, ou seja, empresas formadas com base em empreendedorismo e investimento e as empresas familiares.

No primeiro caso, um dos sócios detém a idéia para a formação de um determinado negócio, enquanto o outro entra em parceria fornecendo o capital necessário para o desenvolvimento dessa idéia.

Até esse momento nenhum problema, eis que ambos os envolvidos sabem o que podem ganhar e o que podem perder acaso o empreendimento venha a frutificar ou dar errado. Porém, imagine-se uma situação em que a idéia inicialmente prospera, rendendo lucros e assegurando o levantamento do investimento inicial. A partir daí costumam surgir problemas pois, não raras vezes, o sócio empreendedor se acha lesado pelo sócio investidor pois, da idéia genial que aquele teve, este não participou.

Os conflitos acabam por gerar reflexos na empresa e, consequentemente, provocam prejuízos, resultando na cisão da empresa, ou ainda, na sua quebra por insolvência ou dissolução judicial.

Há outras hipóteses em que o sócio investidor resolve caminhar por conta própria, pois, afinal, foram seus recursos financeiros que fizeram com que a idéia ganhasse a mídia e rendesse dividendos. A partir daí começa a realizar chamadas de capital com o intuito de excluir o sócio empreendedor pelo uso do poder econômico de que dispõe.

${ }^{13}$ Cf. FRITZ, Karina Nunes. Boa-fé objetiva na fase pré-contratual. Curitiba: Juruá, 2008, pág. 161.

116 Revista Estudos Jurídicos UNESP, Franca, A. 14 n.19, p. 01-404, 2010 
Outra situação em que costuma levantar celeumas nas sociedades empreendedor-investidor são aqueles em que um dos sócios, quando a empresa está em franco desenvolvimento, vem a falecer. Os contratos sociais ou estatutos costumam prever a liquidação das ações do sócio falecido, ou pior, até a extinção da sociedade, ou que na maioria das vezes implica na ruína do empreendimento.

Todas essas situações estariam ressalvadas acaso na constituição da empresa ambos tivessem celebrado um acordo de sócios, no qual se estabelecesse corretamente as hipóteses de retirada de investimentos, dissolução societária, aportes de capital e sucessão.

O acordo de sócios é o instrumento hábil a prever, no momento da constituição da empresa, como serão distribuídos os resultados futuros, como se realizará a remuneração dos sócios na hipótese de lucratividade do empreendimento, como será realizada a distribuição dos lucros, qual o percentual dos lucros será revertido em benefício da expansão da atividade econômica da empresa, como será pago o investimento inicial, etc...

De igual sorte, é no acordo de sócios que estabelece qual a forma de liquidação das ações na hipótese de falecimento de um dos sócios, a possibilidade de sucessão das ações pelos herdeiros, a condição em que esses herdeiros adentrariam à sociedade, enfim, todas as hipóteses para garantir a manutenção da atividade empresarial e a manutenção da empresa.

Já as empresas familiares, geralmente se caracterizam por um empreendimento fundado pelo patriarca ou pela matriarca da família, que hoje, está sendo gerido pelos filhos, filhas, genros e noras. Em geral, todas essas empresas possuem um dos filhos (ou agregado) que é o responsável geral pelos negócios, tendo assumido a posição do patriarca no comando do empreendimento.

Nessa circunstância poderia se cogitar que não haveria problemas, pois sempre haveria quem substituísse o patriarca no comando dos negócios da família, sem maiores surpresas. Porém, não é assim que ocorre na maioria das empresas familiares, havendo uma constante guerra de poderes entre os herdeiros e sucessores do negócio, o que pode ocasionar sérios prejuízos na hipótese de falecimento do patriarca ou da matriarca, os quais, mesmo afastados da gestão da empresa, têm poder de comando sobre seus filhos ou agregados para a solução de eventuais conflitos.

Na hipótese de falecimento do elo comum entre os familiares, não são raras as hipóteses em que a empresa acaba por ruir, pois ela somente se subsiste unida em torno de um único objetivo, com todos os recursos em um só patrimônio, a fim de garantir a sustentabilidade do negócio.

Sendo assim, a ruptura do elo familiar ocasiona a divisão do patrimônio empresarial e, consequentemente, da afinidade entre os sócios sucessores, que pretendem exclusivamente apropriar-se de seu quinhão individual e levar sua vida individualmente. 
Assim, toda empresa familiar deve possuir um plano sucessório, de preferência entabulado entre o patriarca ou matriarca com seus herdeiros, já estabelecendo regras claras de sucessão e distribuição do poder de comando na empresa no caso de falecimento de um deles ou de ambos.

O acordo dessa espécie vem quase sempre acompanhado da formação de sociedades patrimoniais e de outras figuras jurídicas como a doação de cotas e o usufruto, que garantem aos patriarcas a manutenção do poder de gestão enquanto vivos, e a prevalência de sua vontade após seu decesso.

Assim, como se vê, o acordo de sócios, com sua amplitude e abrangência, é um meio eficaz de se prevenir litígios societários, desde que elaborados de comum acordo, em um momento anterior ao litígio, quando as partes ainda estão em harmonia na sociedade.

Agindo dessa forma, a sociedade preservará sua atividade econômica e assegurará a sua perpetuidade.

\section{Conclusão}

A ganância do sócio(s) pelo poder ou pelo dinheiro é, quase sempre, a causa determinante nos litígios societários, não havendo outra maneira de se prevenir essa situação senão a antecipação dos problemas por meio de regras claras constantes de um acordo celebrado, de preferência, no momento da constituição da empresa.

Tanto nas empresas familiares, quando nas aqui classificadas como empreendedor-investidor, pode se antecipar e prevenir litígios, estabelecendo no acordo de sócios uma maneira clara de liquidação da participação societária, ou ainda, da divisão de atividades, lucros ou rentabilidade por trabalho.

O presente estudo serve apenas como um norte para as hipóteses de acordo que podem ser celebradas na amplitude do regramento aplicável, valendo dizer que se não houver prejuízo ao objetivo social da empresa, quase que a totalidade das obrigações é admitida nessa espécie de contrato.

Portanto, antes de ingressar em um empreendimento mercantil que envolva mais de uma pessoa, é prudente a prevenção de todas as espécies de litígios na forma de um acordo de sócios.

\section{Referências Bibliográficas:}

1. BARBI FILHO, Celso. Acordo de acionista. Belo Horizonte: Del Rey, 1993;

2. BERTOLDI, Marcelo M. Acordo de Acionistas. São Paulo: Editora Revista dos Tribunais, 2006;

3. CARVALHOSA, Modesto. Acordo de Acionistas. São Paulo: Saraiva, 1984;

4. COMPARATO, Fabio Konder. Restrições à circulação de ações em companhia fechada: "nova et vetera" Revista de Direito Mercantil, São Paulo: Revista dos Tribunais, $n^{\circ} 36 / 65$ 
5. DINIZ Maria Helena. Código Civil Anotado, $13^{a}$ Edição. São Paulo: Saraiva, 2008;

6. FRITZ, Karina Nunes. Boa-fé objetiva na fase pré-contratual. Curitiba: Juruá, 2008

7. GOMES, Orlando. Contratos. Rio de Janeiro: Forense, 1998;

8. MARTINS-COSTA, Judith. A Boa-Fé no Direito Privado. 1. ed., 2. tiragem. São Paulo: Editora Revista dos Tribunais, 2000;

RODRIGUES, Silvio, Direito Civil, Volume 3. São Paulo: Saraiva 
